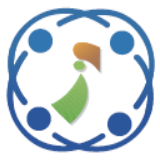

\title{
Adaptive Field-Oriented Control Using Supervisory Type-2 Fuzzy Control for Dual Star Induction Machine
}

\author{
Hilal Rahali ${ }^{1 *}$ Samir Zeghlache ${ }^{2} \quad$ Leila Benalia $^{3}$ \\ ${ }^{1}$ Laboratoire de génie élecrtique, Department of Electrical Engineering, Faculty of Technology, University \\ Mohamed Boudiaf of M'sila, BP 166, Ichbilia 28000, Algeria \\ ${ }^{2}$ Laboratoire d'analyse des signaux et systèmes, Department of Electronics, Faculty of Technology, University \\ Mohamed Boudiaf of M'sila, BP 166, Ichbilia 28000, Algeria \\ ${ }^{3}$ Laboratoire de génie élecrtique, Department of Electrical Engineering, Batna-2 University, Street Chahid Med \\ El Hadi boukhlouf, Algeria \\ * Corresponding author's Email: hilal_lami@yahoo.fr
}

\begin{abstract}
This paper proposes Interval Type-2 Fuzzy Gain-Adaptive PI (IT2FGAPI) controller based on direct field oriented control (DRFOC), to control the speed of a dual star induction machine (DSIM), to get a robust performance machine. We use IT2FGAPI for speed control of the DSIM corresponding to adapting the different gains $K_{p}$ and $K_{i}$ corresponding the different PI logic, PI of speed, PI of flux and the four PI of currents in a vector control mode. An interval type-2 fuzzy control system is used to adapt in real-time the controller gains, to generate the PI controller parameters, he gives a fast dynamic response with no overshoot, robust and their performances are insensible to parameter variations, at different dynamic operating such as sudden change in command speed, step change in load torque and some key parameters deviation. The simulations results obtained from MatLab/Simulink are finally presented and discussed; the obtained results show that the controller in enhancing the robustness of control systems with high accuracy.
\end{abstract}

Keywords: Interval Type-2 Fuzzy, Gain-Adaptive PI, IT2FGAPI, direct field oriented control, DSIM, speed control.

\section{Introduction}

Dual star induction machines (DSIM) have been used in many industrial applications due to their performances in high power fields and for highpower applications such as electric hybrid vehicles, locomotive traction and electric ship propulsion[1-5], and has many advantages, not only does give reduced torque pulsation, reduced rotor harmonics as they can be filtered and power segmentation but it also requires less powerful electronic components as the current flowing in a six-phase machine is less than that flowing in a three-phase machine [4] [6-9].

The field oriented control (FOC) of with a conventional PI speed controller is required in principle by some industrial processes and in research over the last decade. It is easy to design and implement, but it has difficulty in dealing with parameter variations, and load disturbances $[10,11]$. The control objective is to produce of control decoupled of the flux and the torque of the DSIM like DC motors [7], [12].

With the problems posed by the variations of the operating points of the system, the PI controllers lose their performance and should be badly regulated, to avoid this, the fuzzy adapts the parameters of PI controller by providing optimal PI controller settings automatically to measure these parameters, and these optimal settings of the PI controller are called nonlinear adaptive PI.

The use of the adaptive type-2 fuzzy control in the industrial application obviously prevents a heavy computation burden; it is performance better than the traditional adaptive fuzzy control [13].

Our purpose in this paper is to introduce an IT2FGAPI control for DSIM drive system for the DRFOC approach; the fuzzy inference adjusts the PI 
parameters and adapts the $K_{p}$ and $K_{i}$ during process control.

The proposed method is applied to dual star induction machine to control the speed and flux as a one advanced control strategy, to solve the problem of the robustness of the speed control of a DSIM by the determination systematical the gains $\left(K_{p}, K_{i}\right)$, based on the error signal and its first difference, in the direct field oriented control while guaranteeing the stability, and ensures robust and their performances insensible during internal and external disturbances (Sudden change in command speed, step change in load torque...) contrary to conventional regulators.

The main advantage of this adaptation is to synthesize the six gains corresponding the different PI logic (PI of speed, PI of flux and the four PI of currents) in the same time and in the same way, contrary of several researchers and methods in regards to the adaptation of the gain of a single PI that of speed, and used the type 1-fuzzy control [1416]. The obtained results show the efficacy of the proposed method by another method [14], because he gives a fast dynamic response with no overshoot, robust and their performances are insensible of the sudden change in command speed, step change in load torque.

The remainder of the paper is organized as follows. The system description and modeling of the DSIM given is Section 2. The vector control by direct rotor flux orientation is stated in Section 3. The Background of Type-2 Fuzzy Control Logic is proposed in Section 4. The section 5 explains the principles IT2FGAPI for regulate the speed of the DSIM by the technique of artificial intelligence. Simulation results used the IT2FGAPI presents in section 6. Finally, conclusion is given in section 7 .

\section{Description and modelling of DSIM}

The dual star induction machine is composed by two stars separate with three phases winding fixed and standard simple squirrel-cage rotor composed three rotors phases moving. The two stators is displaced by angle $(\alpha=\pi / 6)$, their axes are shifted from each other an electrical angle equal to $(2 \pi / 3)$ with isolated neutrals [7], [17]. Therefore, the orthogonality created between the two oriented fluxes, which must be strictly observed, leads to generate decoupled control with an optimal torque[3], [18]. The windings of the DSIM are represented in fig. 1.

The following assumptions have been made in deriving the machine model [19]:

- Motor windings are sinusoidal distributed.
- The two stars have same parameters,

- Flux path is linear.

-The magnetic saturation and the mutual leakage are neglected.

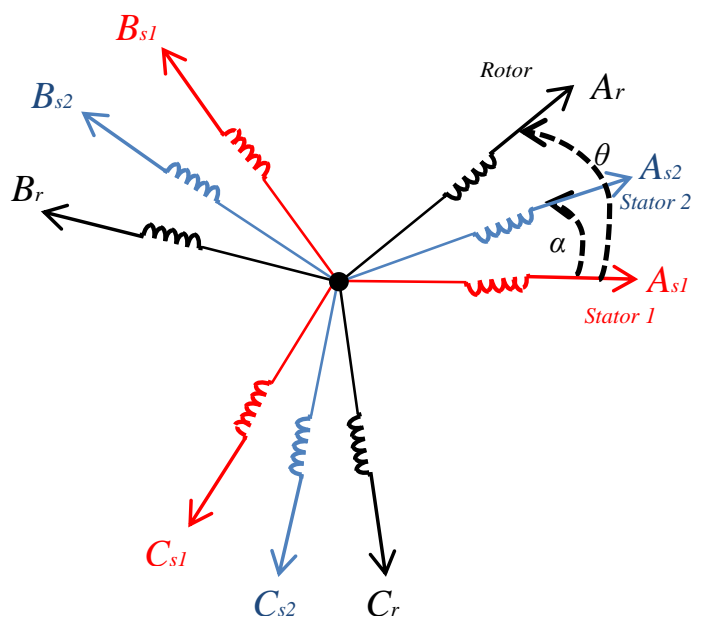

Figure.1 Representation of the DSIM winding

\subsection{DSIM Model in the reference $(d, q)$}

In the references related at the rotating field (d, q), the Park model of DSIM is presented below:

a / Electrical equations

$$
\left\{\begin{array}{l}
V_{d s 1}=R_{s 1} I_{d s 1}+\frac{d}{d t} \varphi_{d s 1}-\omega_{s} \varphi_{q s 1} \\
V_{q s 1}==R_{s 1} I_{q s 1}+\frac{d}{d t} \varphi_{q s 1}+\omega_{s} \varphi_{d s 1} \\
V_{d s 2}==R_{s 2} I_{d s 2}+\frac{d}{d t} \varphi_{d s 2}-\omega_{s} \varphi_{q s 2} \\
V_{q s 2}=R_{s 2} I_{q s 2}+\frac{d}{d t} \varphi_{q s 2}+\omega_{s} \varphi_{d s 2} \\
0=R_{r} I_{d r}+\frac{d}{d t} \varphi_{d r}+\left(\omega_{s}-\omega_{r}\right) \varphi_{q r} \\
0=R_{r} I_{q r}+\frac{d}{d t} \varphi_{q r}+\left(\omega_{s}-\omega_{r}\right) \varphi_{d r}
\end{array}\right.
$$

$\mathrm{b} /$ The fluxes equations

$$
\left\{\begin{array}{l}
\varphi_{d s 1}=L_{s 1} I_{d s 1}+L_{m}\left(I_{d s 1}+I_{d s 2}+I_{d r}\right) \\
\varphi_{d s 2}=L_{s 2} I_{d s 2}+L_{m}\left(I_{d s 2}+I_{d s 1}+I_{d r}\right) \\
\varphi_{q s 1}=L_{s 1} I_{q s 1}+L_{m}\left(I_{q s 1}+I_{q s 2}+I_{d r}\right) \\
\varphi_{q s 2}=L_{s 2} I_{q s 2}+L_{m}\left(I_{q s 2}+I_{q s 1}+I_{q r}\right) \\
\varphi_{d r}=L_{r} I_{d r}+L_{m}\left(I_{d r}+I_{d s 1}+I_{d s 2}\right) \\
\varphi_{q r}=L_{r} I_{q r}+L_{m}\left(I_{q r}+I_{q s 1}+I_{q s 2}\right)
\end{array}\right.
$$

The electromagnetic torque of DSIM is given by [9, 15, 17]: 
$J \frac{d \Omega}{d t}=C_{e m}-C_{r}-K_{f} \Omega$

With:

$C_{e m}=p \frac{L_{m}}{L_{m}+L_{r}}\left[\varphi_{d r}\left(I_{q s 1}+I_{q s 2}\right)-\varphi_{q r}\left(I_{d s 1}+I_{d s 2}\right)\right]$

\subsection{State equation of the DSIM model}

The electrical state variables are written at utilized both for the electrical and mechanical parts are representing in the following form: $d X / d t=$ $A X+B U$

$\frac{d}{d t}[\varphi]=A \cdot[\varphi]+B \cdot[V]$

With $X, A, B$ and $U$ represent the state vector, system state evolution matrix, matrix of control and vector of the control system respectively.

We choose in all the following, the state vector:

$U=\left[\begin{array}{l}v_{d s 1} \\ v_{d s 2} \\ v_{q s 1} \\ v_{q s 2} \\ 0 \\ 0\end{array}\right]$

$$
X=\left[\begin{array}{c}
\varphi_{d s 1} \\
\varphi_{d s 2} \\
\varphi_{q s 1} \\
\varphi_{q s 2} \\
\varphi_{d r} \\
\varphi_{q r}
\end{array}\right]
$$

From Eq. (2), the different currents are expressed as follows:

$$
\left\{\begin{array}{l}
I_{d s 1}=\frac{\varphi_{d s 1}-\varphi_{m d}}{L_{s 1}} \\
I_{d s 2}=\frac{\varphi_{d s 2}-\varphi_{m d}}{L_{s 2}} \\
I_{q s 1}=\frac{\varphi_{q s 1}-\varphi_{m q}}{L_{s 1}} \\
I_{q s 2}=\frac{\varphi_{q s 2}-\varphi_{m q}}{L_{s 2}} \\
I_{d r}=\frac{\varphi_{d r}-\varphi_{m d}}{L_{r}} \\
I_{q r}=\frac{\varphi_{q r}-\varphi_{m q}}{L_{r}}
\end{array}\right.
$$

We pose:

$$
\left\{\begin{array}{l}
\varphi_{m d}=L_{a}\left(\frac{\varphi_{d s 1}}{L_{s 1}}+\frac{\varphi_{d s 2}}{L_{s 2}}+\frac{\varphi_{d r}}{L_{r}}\right) \\
\varphi_{m q}=L_{a}\left(\frac{\varphi_{q s 1}}{L_{s 1}}+\frac{\varphi_{q s 2}}{L_{s 2}}+\frac{\varphi_{q r}}{L_{r}}\right)
\end{array}\right.
$$

Or:

$$
L_{a}=\frac{1}{\frac{1}{L_{s 1}}+\frac{1}{L_{s 2}}+\frac{1}{L_{r}}+\frac{1}{L_{m}}}
$$

By replacing the system of Eq. (9) in Eq. (8) and then in system of Eq. (1) we shall have:

$$
\left\{\begin{aligned}
\frac{d}{d t} \varphi_{d s 1}= & V_{d s 1}-\left(\frac{R_{s 1}}{L_{s 1}}-\frac{R_{s 1} L_{a}}{L_{s 1}^{2}}\right) \varphi_{d s 1}+\frac{R_{s 1} L_{a}}{R_{s 1} L_{s 2}} \varphi_{d s 2}+ \\
& \omega_{s} \varphi_{q s 1}+\frac{R_{s 1} L_{a}}{R_{r} L_{s 1}} \varphi_{d r} \\
\frac{d}{d t} \varphi_{d s 2}= & V_{d s 2}-\left(\frac{R_{s 2}}{L_{s 2}}-\frac{R_{s 2} L_{a}}{L_{s 2}^{2}}\right) \varphi_{d s 2}+\frac{R_{s 2} L_{a}}{R_{s 1} L_{s 2}} \varphi_{d s 1}+ \\
& \omega_{s} \varphi_{q s 2}+\frac{R_{s 2} L_{a}}{R_{r} L_{s 2}} \varphi_{d r} \\
& \omega_{s} \varphi_{d s 1}+\frac{R_{s 1} L_{a}}{R_{r} L_{s 1}} \varphi_{q r} \\
\frac{d}{d t} \varphi_{q s 1}= & V_{q s 1}-\left(\frac{R_{s 1}}{L_{s 1}}-\frac{R_{s 1} L_{a}}{L_{s 1}^{2}}\right) \varphi_{q s 1}+\frac{R_{s 1} L_{a}}{R_{s 1} L_{s 2}} \varphi_{q s 2}- \\
& \left(\omega_{s}-\omega\right) \varphi_{d r}+\frac{R_{r} L_{a}}{L_{r} L_{s 2}} \varphi_{q s 2} \\
& \omega_{s} \varphi_{d s 2}+\frac{R_{s 2} L_{a}}{R_{r} L_{s 2}} \varphi_{q r} \\
\frac{d}{d t} \varphi_{q s 2}= & V_{q s 2}-\left(\frac{R_{s 2}}{L_{s 2}}-\frac{R_{s 2} L_{a}}{L_{s 2}^{2}}\right) \varphi_{q s 2}+\frac{R_{s 2} L_{a}}{R_{s 1} L_{s 2}} \varphi_{q s 1}- \\
& \left(\omega_{s}-\omega\right) \varphi_{q r}+\frac{R_{r} L_{a}}{R_{r} L_{s 2}} \varphi_{d s 2} \\
\left.\frac{R_{r} L_{a}}{L_{r}^{2}}\right) \varphi_{d r}+\frac{R_{r} L_{a}}{R_{r} L_{s 1}} \varphi_{d s 1}+ & -\left(\frac{R_{r}}{L_{r}}-\frac{R_{r} L_{a}}{L_{r}^{2}}\right) \varphi_{q r}+\frac{R_{r} L_{a}}{L_{r} L_{s 2}} \varphi_{q s 1}- \\
\varphi_{d r}= & \left(\frac{R_{r}}{d t}=\right.
\end{aligned}\right.
$$

Finally, we put the system of Eq. (11) as Eq. (5)

$$
B=\left(\begin{array}{llllll}
1 & 0 & 0 & 0 & 0 & 0 \\
0 & 1 & 0 & 0 & 0 & 0 \\
0 & 0 & 1 & 0 & 0 & 0 \\
0 & 0 & 0 & 1 & 0 & 0 \\
0 & 0 & 0 & 0 & 0 & 0 \\
0 & 0 & 0 & 0 & 0 & 0
\end{array}\right)
$$




$$
\begin{aligned}
& A=\left(\begin{array}{llllll}
a_{11} & a_{12} & a_{13} & a_{14} & a_{15} & a_{16} \\
a_{21} & a_{22} & a_{23} & a_{24} & a_{25} & a_{26} \\
a_{31} & a_{32} & a_{33} & a_{34} & a_{35} & a_{36} \\
a_{41} & a_{42} & a_{43} & a_{44} & a_{45} & a_{46} \\
a_{51} & a_{52} & a_{53} & a_{54} & a_{55} & a_{56} \\
a_{61} & a_{62} & a_{63} & a_{64} & a_{65} & a_{66}
\end{array}\right) \\
& a_{11}=a_{33}=\frac{R_{s 1} L_{a}}{L_{s 1}{ }^{2}}-\frac{\mathrm{R}_{\mathrm{s} 1}}{\mathrm{~L}_{\mathrm{s} 1}} \quad ; \quad a_{12}=a_{34}=\frac{R_{s 1} L_{a}}{L_{s 1} L_{s 2}} \\
& a_{22}=a_{44}=\frac{R_{s 2} L_{a}}{L_{s 2}{ }^{2}}-\frac{\mathrm{R}_{\mathrm{s} 2}}{\mathrm{~L}_{\mathrm{s} 2}} \quad ; \quad a_{15}=a_{36}=\frac{R_{s 1} L_{a}}{L_{s 1} L_{r}} \\
& a_{25}=a_{46}=\frac{R_{s 2} L_{a}}{L_{s 2} L_{r}} \quad ; \quad a_{21}=a_{43}=\frac{R_{s 2} L_{a}}{L_{s 1} L_{s 2}} \\
& a_{52}=a_{64}=\frac{R_{r} L_{a}}{L_{s 2} L_{r}} \quad ; \quad a_{51}=a_{63}=\frac{R_{r} L_{a}}{L_{s 1} L_{r}} \\
& a_{55}=a_{66}=\frac{R_{r} L_{a}}{L_{r}{ }^{2}}-\frac{\mathrm{R}_{\mathrm{r}}}{\mathrm{L}_{\mathrm{r}}} \quad ; \quad a_{13}=a_{24}=-a_{31}=-a_{42}=\omega_{s} \\
& a_{56}=-a_{65}=\omega_{g l} \quad ; \quad \omega_{\text {glref }}=\omega_{\text {sref }}-\omega_{r} \\
& a_{14}=a_{16}=a_{23}=a_{26}=a_{32}=a_{35}=a_{41}=a_{45}=a_{53}= \\
& a_{54}=a_{61}=a_{62}=0
\end{aligned}
$$

\section{Vector control by direct rotor flux orientation}

The principle of vector control consists in orienting one of the stator, rotor or air gap components on an axis of the reference frame rotating at the speed machine $\omega$.

To simplify the control of the DISM, we are selected to the rotating field with an orientation of the flux rotor, since this leads for achieve to a speed variation where the flux and the electromagnetic torque are independently controlled through the stator currents, to assimilate the operating mode of the asynchronous machine at the one of a DC machine with separated excitation [20].

The control strategy used to maintain: $\varphi_{d r}=\varphi$ and $\varphi_{q r}=0$. The Rotor flux Orientation of the DSIM is represented in fig. 2 .

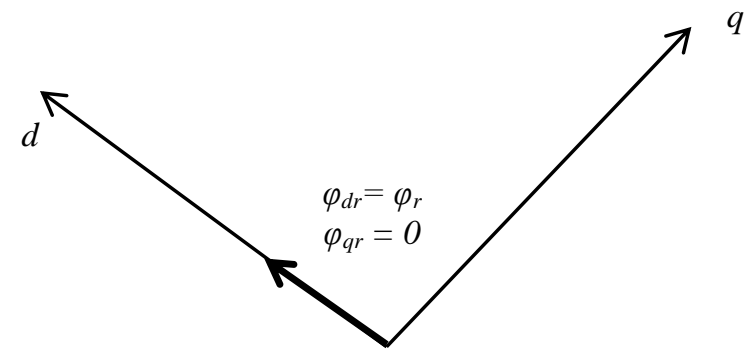

Figure.2 Rotor flux Orientation

\subsection{The final different equations}

By applying the orientation of the rotor flux, consider the rotor flux $\varphi_{\text {rref }}$ and the torque $C_{\text {emref }}$ as control references. The direct axis d coincides with the vector of the rotor flux $\varphi_{r}$, taking into account the condition: $\varphi_{d r}=\varphi_{\text {rref }}$ and $\varphi_{q r}=0$.

$\left\{\begin{array}{l}I_{d r}=\frac{\varphi_{d r}-L_{m}\left(I_{d s 1}+I_{d s 2}\right)}{L_{r}+L_{m}} \\ I_{q r}=\frac{\varphi_{q r}-L_{m}}{L_{r}+L_{m}}\left(I_{q s 1}+I_{q s 2}\right)\end{array}\right.$

By replacing Eq. (14) in Eq. (2) we obtain Eq. (15):

$\left\{\begin{array}{l}\varphi_{d s 1}=\lambda_{1} I_{d s 1}+L_{r} \eta I_{d s 2}+\eta \varphi_{r r e f} \\ \varphi_{q s 1}=\lambda_{1} I_{q s 1}+L_{r} \eta I_{q s 2} \\ \varphi_{d s 2}=\lambda_{2} I_{d s 2}+L_{r} \eta I_{d s 1}+\eta \varphi_{r r e f} \\ \varphi_{q s 2}=\lambda_{2} I_{q s 2}+L_{r} \eta I_{q s 1}\end{array}\right.$

With:

$$
\begin{aligned}
& \eta=\frac{L_{m}}{L_{r}+L_{m}} ; \lambda_{1,2}=L_{s 1,2}+\eta L_{r} \\
& \varphi_{r r e f}=L_{m}\left(I_{d s 1}+I_{d s 2}\right) \\
& I_{q r}=-\frac{L_{m}}{L_{r}+L_{m}}\left(I_{q s 1}+I_{q s 2}\right)
\end{aligned}
$$

The relation of the rotor current is:

$$
I_{q r}=\frac{-\omega_{\text {glref }} \varphi_{\text {ref }}}{R_{r}}
$$

By replacing Eq. (15), Eq. (16) and Eq. (17) in Eq. (1), we obtain Eq. (18). 


$$
\left\{\begin{aligned}
V_{d s 1 \text { ref }}= & R_{s 1} I_{d s 1}+L_{s 1} \frac{d}{d t} I_{d s 1}- \\
& \omega_{s r e f}\left(L_{s 1} I_{q s 1}+T_{r} \varphi_{r r e f} \omega_{g l r e f}\right) \\
V_{q s 1 r e f}= & R_{s 1} I_{q s 1}+L_{s 1} \frac{d}{d t} I_{q s 1}+ \\
& \omega_{s r e f}\left(L_{s 1} I_{d s 1}+\varphi_{r r e f}\right) \\
= & R_{s 2} I_{d s 2}+L_{s 2} \frac{d}{d t} I_{d s 2}- \\
& \omega_{s r e f}\left(L_{s 2} I_{q s 2}+T_{r} \varphi_{r r e f} \omega_{g l r e f}\right) \\
V_{d s 2 r e f} & R_{s 2} I_{q s 2}+L_{s 2} \frac{d}{d t} I_{q s 2}+ \\
& \omega_{s r e f}\left(L_{s 2} I_{d s 2}+\varphi_{r r e f}\right)
\end{aligned}\right.
$$

Where: $T_{r}=\frac{L_{r}}{R_{r}} \quad ; \quad \omega_{\text {glref }}=\omega_{\text {sref }}-\omega_{r}$

$$
\left\{\begin{array}{l}
\omega_{g l r e f}=\frac{R_{r} L_{m}}{\left(L_{m}+L_{r}\right) \varphi_{\text {ref }}}\left(I_{q s 1}+I_{q s 2}\right) \\
I_{q s 1}+I_{q s 2}=\frac{L_{r}+L_{m}}{p L_{m} \varphi_{\text {rref }}} C_{e m r e f}
\end{array}\right.
$$

So the torque equation becomes:

$$
C_{\text {emref }}=p \frac{L_{m}}{L_{r}+L_{m}} \varphi_{r r e f}\left(I_{q s 1}+I_{q s 2}\right)
$$

This expression of the torque (Eq. (20)) clearly shows the dependence between the quadrature stator currents and the reference flux, because of this, we thus define a new system to decouple the control of the torque and that of the flux of this machine by introducing new variables:

$$
\left\{\begin{array}{l}
V_{d s 1}=R_{s 1} I_{d s 1}+L_{s 1} \frac{d}{d t} I_{d s 1} \\
V_{d s 2}=R_{s 2} I_{d s 2}+L_{s 2} \frac{d}{d t} I_{d s 2} \\
V_{q s 1}=R_{s 1} I_{q s 1}+L_{s 1} \frac{d}{d t} I_{q s 1} \\
V_{q s 2}=R_{s 2} I_{q s 2}+L_{s 2} \frac{d}{d t} I_{q s 2}
\end{array}\right.
$$

According to the system of Eq. (21), there is a liaison between the voltages and the stator currents, in other words, between flux and torque. Therefore, in this case, decoupling is very important, following the vector control of direct rotor flux orientation.

To compensate for the error introduced during decoupling, the reference stator voltages ( $v_{d s}$ ref, $\left.v_{d s 2 r e f}, v_{q s 1 r e f}, v_{q s 2 r e f}\right)$ are given by: [21]

$$
\begin{aligned}
& \left\{\begin{array}{l}
V_{d s 1 \text { ref }}=V_{d s 1}-V_{d s 1 c} \\
V_{q s 1 r e f}=V_{q s 1}-V_{q s 1 c} \\
V_{d s 2 r e f}=V_{d s 2}+V_{d s 2 c} \\
V_{q s 2 r e f}=V_{q s 1}+V_{q s 1 c}
\end{array}\right. \\
& \left\{\begin{array}{l}
V_{d s 1 c}=\omega_{\text {sref }}\left(L_{s 1} I_{q s 1}+T_{r} \varphi_{\text {rref }} \omega_{g \text { lref }}\right) \\
V_{q s 1 c}=\omega_{\text {sref }}\left(L_{s 1} I_{d s 1}+\varphi_{\text {rref }}\right) \\
V_{d s 2 c}=\omega_{\text {sref }}\left(L_{s 2} I_{q s 2}+T_{r} \varphi_{\text {rref }} \omega_{g l r e f}\right) \\
V_{q s 2 c}=\omega_{\text {sref }}\left(L_{s 2} I_{d s 2}+\varphi_{\text {rref }}\right)
\end{array}\right.
\end{aligned}
$$

For perfect decoupling, we are added the stator current regulation loops [22].

Accepting that: $I_{d s I r e f}=I_{d s 2 \mathrm{ref}}$ and $I_{q s \text { ref }}=I_{q s 2 \mathrm{ref}}$.

\subsection{The Rotor flux estimator}

Precise knowledge of the amplitude and the position of the rotor flux vector are necessary [23], for this purpose a flux estimator is implemented, this method eliminates the need to use a flux sensor.

The rotor flux is estimated by the following equations:

$$
\left\{\begin{aligned}
\frac{d \varphi_{\text {drest }}}{d t}= & \frac{R_{r} L_{m}}{L_{r}+L_{m}}\left(I_{d s 1}+I_{d s 2}\right)+\omega_{\text {glref }} \varphi_{\text {qrest }}- \\
& \frac{R_{r}}{L_{r}+L_{m}} \varphi_{\text {drest }} \\
\frac{d \varphi_{\text {qrest }}}{d t}= & \frac{R_{r} L_{m}}{L_{r}+L_{m}}\left(I_{q s 1}+I_{q s 2}\right)-\omega_{\text {glref }} \varphi_{\text {drest }}- \\
& \frac{R_{r}}{L_{r}+L_{m}} \varphi_{\text {qrest }}
\end{aligned}\right.
$$

The rotor flux modulus is calculated by:

$$
\varphi_{\text {rest }}=\sqrt{\varphi_{\text {drest }}^{2}+\varphi_{\text {qrest }}^{2}}
$$

The DRFOC is introduced as shown in Fig. 3.

\section{Background of Type-2 Fuzzy Logic Control}

Type-1 and type-2 fuzzy logic are mainly similar. However, there exist two essential differences between them which are: the membership functions shape and the output processor. Indeed, an interval type-2 fuzzy controller is consisting of: a fuzzifier, an inference engine, a rules base, a type reduction and a defuzzyfier. 


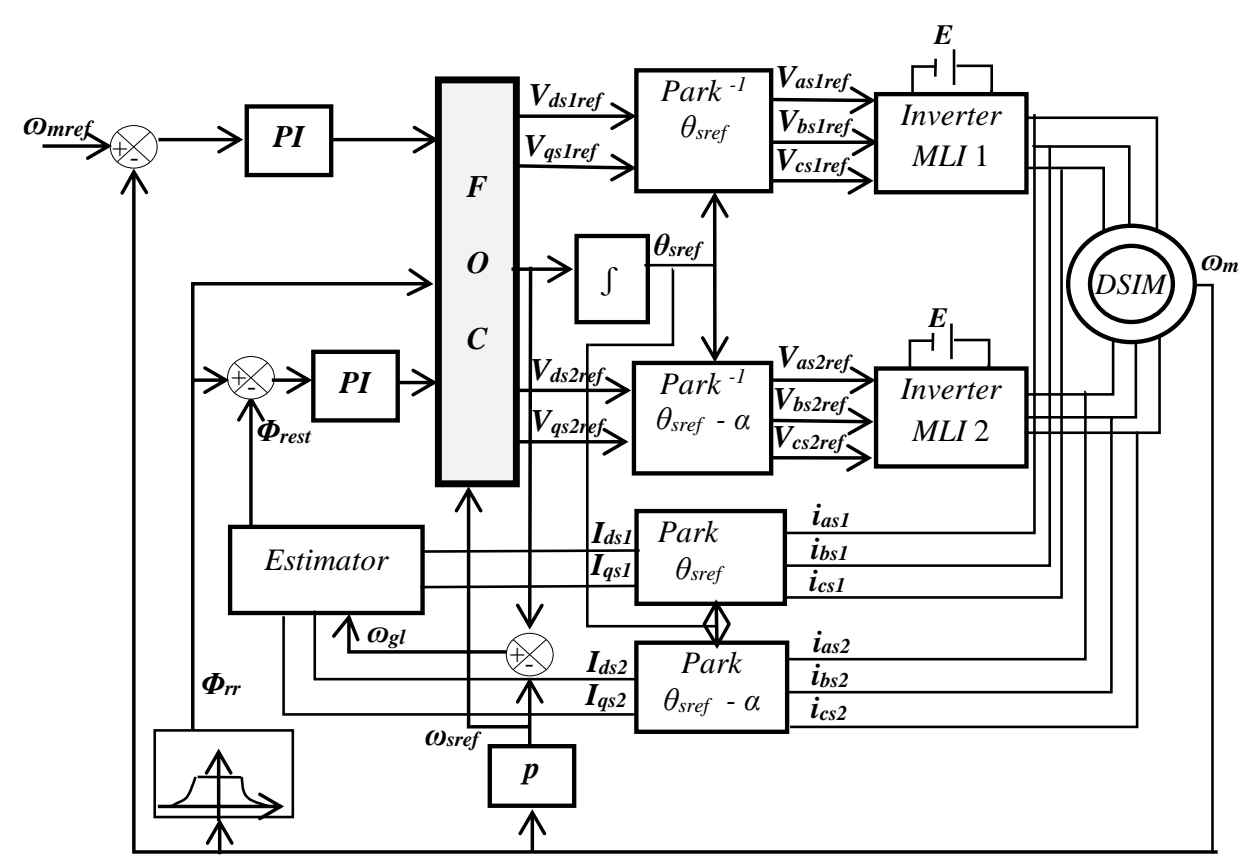

Figure.3 Direct rotor field orientation control

\subsection{Fuzzifier}

The fuzzifier maps the crisp input vector $\left(e_{1}, e_{2}\right.$, $\left.e_{n}\right)^{T}$ to a type-2 fuzzy system $\tilde{A}_{x}$, very similar to the procedure performed in a type-1 fuzzy logic system.

\subsection{Rules}

The general form of the $i_{t h}$ rule of the type- 2 fuzzy logic system can be written as:

$$
\begin{aligned}
& \text { If } e_{1} i s \tilde{F}_{1}^{i} \text { and } e_{2} i s \tilde{F}_{1}^{i} \text { and } \ldots e_{n} i \text { is } \tilde{F}_{n}^{i}, \\
& \text { than } y^{i}=\tilde{G}^{i} \quad i=1, \ldots, M
\end{aligned}
$$

Where: $\tilde{F}_{i j}$ represent the type-2 fuzzy system of the input state $j$ of the $i^{\text {th }}$ rule, $x_{1}, x_{2}, \ldots, x_{n}$ are the inputs, $\tilde{G}^{i}$ is the output of type-2 fuzzy system for the rule $i$, and $M$ is the number of rules. As can be seen, the rule structure of type-2 fuzzy logic system is similar to type-1 fuzzy logic system except that type-1 membership functions are replaced with their type- 2 counterparts.

\subsection{Inference Engine}

In fuzzy system interval type-2 using the minimum or product t-norms operations, the $i^{\text {th }}$ activated rule $F^{i}\left(x_{1}, \ldots, x_{n}\right)$ gives us the interval that is determined by two extremes $\underline{\underline{f}}^{i}\left(x_{1}, \ldots, x_{n}\right)$ and $\bar{f}$ ${ }^{i}\left(x_{1}, \ldots, x_{n}\right)[24]$ :

$$
\begin{aligned}
F^{i}\left(x_{1}, \ldots x_{n}\right) & =\left[\underline{f}^{i}\left(x_{1}, \ldots x_{n}\right), \bar{f}^{i}\left(x_{1}, \ldots x_{n}\right)\right] \\
& \equiv\left[f^{i}, \bar{f}^{i}\right]
\end{aligned}
$$

With: $\underline{\underline{f}}^{i}$ and $\bar{f}^{i}$ are given as:

$$
\begin{aligned}
& f^{i}=\underline{\mu}_{F_{1}^{i}}\left(x_{1}\right) * \ldots * \underline{\mu}_{F_{n}^{i}}\left(x_{n}\right) \\
& \bar{f}^{i}=\bar{\mu}_{F_{1}^{i}}\left(x_{1}\right) * \ldots * \bar{\mu}_{F_{n}^{i}}\left(x_{n}\right)
\end{aligned}
$$

\subsection{Type Reducer}

After the rules are fired and inference is executed, the obtained type- 2 fuzzy system resulting in type- 1 fuzzy system is computed. In this part, the available methods to compute the centroid of type- 2 fuzzy system using the extension principle [25] are discussed. The centroid of type-1 fuzzy system A is given by:

$C_{A}=\frac{\sum_{i=1}^{n} z_{i} w_{i}}{\sum_{i=1}^{n} w_{i}}$

Where: $n$ represents the number of discretized domain of $\mathrm{A}, z_{i} \in R$ and $w_{i} \in[0,1]$.

If each $z_{i}$ and $w_{i}$ are replaced with a type-1 fuzzy system $Z_{i}$ and $W_{i}$, with associated membership 
functions of $\mu_{z}\left(z_{i}\right)$ and $\mu_{w}\left(W_{i}\right)$ respectively, by using the extension principle, the generalized centroid for type- 2 fuzzy system $\tilde{A}$ is given by:

$$
\begin{aligned}
G C_{\tilde{A}} & =\int_{z_{1} \in Z_{1}} \ldots \int_{z_{n} \in Z_{n}} \int_{w_{1} \in W_{1}} \ldots \\
& \int_{w_{n} \in W_{n}}\left[T_{i=1}^{n} \mu_{Z}\left(z_{i}\right) * T_{i=1}^{n} \mu_{W}\left(z_{i}\right)\right] / \frac{\sum_{i=1}^{n} z_{i} w_{i}}{\sum_{i=1}^{n} w_{i}}
\end{aligned}
$$

$\mathrm{T}$ is a t-norm and $G C_{\tilde{A}}$ is a type- 1 fuzzy system. For an interval type-2 fuzzy system:

$$
\begin{aligned}
& G C_{\tilde{A}}=\left[y_{l}(x), y_{r}(x)\right] \\
& =\int_{y^{1} \in\left[y_{i}^{1}, y_{r}^{1}\right]} \cdots \int_{y^{M} \in\left[y_{l}^{M}, y_{r}^{M}\right]} \cdots \int_{f^{1} \in\left[f^{1}, f^{1}\right]} \cdots \\
& \int_{f^{M} \in\left[\underline{t}^{M} \bar{f}^{M}\right]} 1 / \frac{\sum_{i=1}^{M} f^{i} y^{i}}{\sum_{i=1}^{M} f^{i}}
\end{aligned}
$$

\subsection{Deffuzzifier}

To get a crisp output from a type-1 fuzzy logic system, the type-reduced set must be defuzzied. The most common method to do this is to find the centroid of the type-reduced set. If the type-reduced set $Y$ is discredited to $n$ points, then the following expression gives the centroid of the type-reduced set as:

$$
y_{\text {ouput }}(x)=\frac{\sum_{i=1}^{n} y^{i} \mu\left(y^{i}\right)}{\sum_{i=1}^{m} \mu\left(y^{i}\right)}
$$

We can compute the output using the iterative Karnik Mendel Algorithms [26-30]. Therefore, the defuzzified output of an interval type-2 FLC is:

$Y_{\text {output }}(x)=\frac{y_{l}(x)+y_{r}(x)}{2}$

With: $y_{l}(x)=\frac{\sum_{i=1}^{M} f_{l}{ }^{i} y_{l}^{i}}{\sum_{i=1}^{M} f_{l}{ }^{i}}$ and $y_{r}(x)=\frac{\sum_{i=1}^{M} f_{r}^{i} y_{l}^{i}}{\sum_{i=1}^{M} f_{r}^{i}}$

\section{IT2FGAPI strategy}

The classic numerical PI (Proportional and Integral) the most primitive, simple controller and easy to use, for this it is widely used in industrial control systems. With the problems posed by changes in system dynamics, their performance may even lead to system instability and the parameters of PI controller should be badly regulated, so cannot always effectively control systems.

Therefore due to the significant impact of two parameters $\left(K_{p}, K_{i}\right)$ and the success of the controller, they must be determined correctly. To overcome this drawback, IT2FGAPI Controller is used to tune PI gains online. The Structure of IT2FGAPI Controller is presented in Fig. 4 [31].

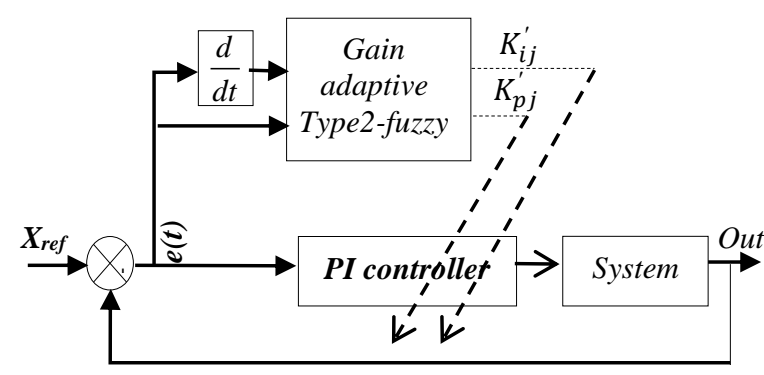

Figure. 4 The gain adaptive mechanism of type2-fuzzy

\subsection{Interval type-2 fuzzy gain adaptive PI}

The proposed control (IT2FGAPI) is an approach to systematically determine the gains $K_{p}$ and $K_{i}$, so that the IT2FGAPI Controller is used to tune PI gains online where the tracking error and its first time difference are used to determine control parameters. The fuzzy tuner has two inputs, error $(e)$ and error derivative $(\Delta e)$, and two outputs, $K_{p}$ and $K_{i}$.

The parameters of the PI controller used in the direct chain, $K_{p}$ and $K_{i}$, are normalized into the range between zero and one by using the following linear transformations [14] [31, 32]:

$\left\{\begin{array}{l}K_{p}^{\prime}=\left(K_{p}-K_{P \min }\right) /\left(K_{P \max }-K_{P \min }\right) \\ K_{i}^{\prime}=\left(K_{i}-K_{i \min }\right) /\left(K_{i \max }-K_{i \min }\right)\end{array}\right.$

The parameters $K_{p}$ and $K_{i}$ are determined by a set of linguistic rules of the IT2FGAIP controller structure, as following:

If $e(k)$ is $A_{i}$, and $\Delta e(k)$ is $B_{i}$, then $K_{p}^{\prime}$ is $C_{i}$, and $K_{i}^{\prime}$ is $D_{i}$.

Where: $A_{i}, B_{i}, C_{i}$ and $D_{i}$ are fuzzy sets corresponding to $e(k), \Delta e(k), K_{p}$ and $K_{i}$ respectively.

The application of the IT2FGAPI control for the DISM corresponding to adapting the different gains $K_{p}$ and $K_{i}$ corresponding the different PI logic, PI of speed, PI of flux and the four PI of currents $\left(I_{d s}, I_{d s 2}\right.$, $I_{q s l}$ and $I_{q s 2}$ ). 


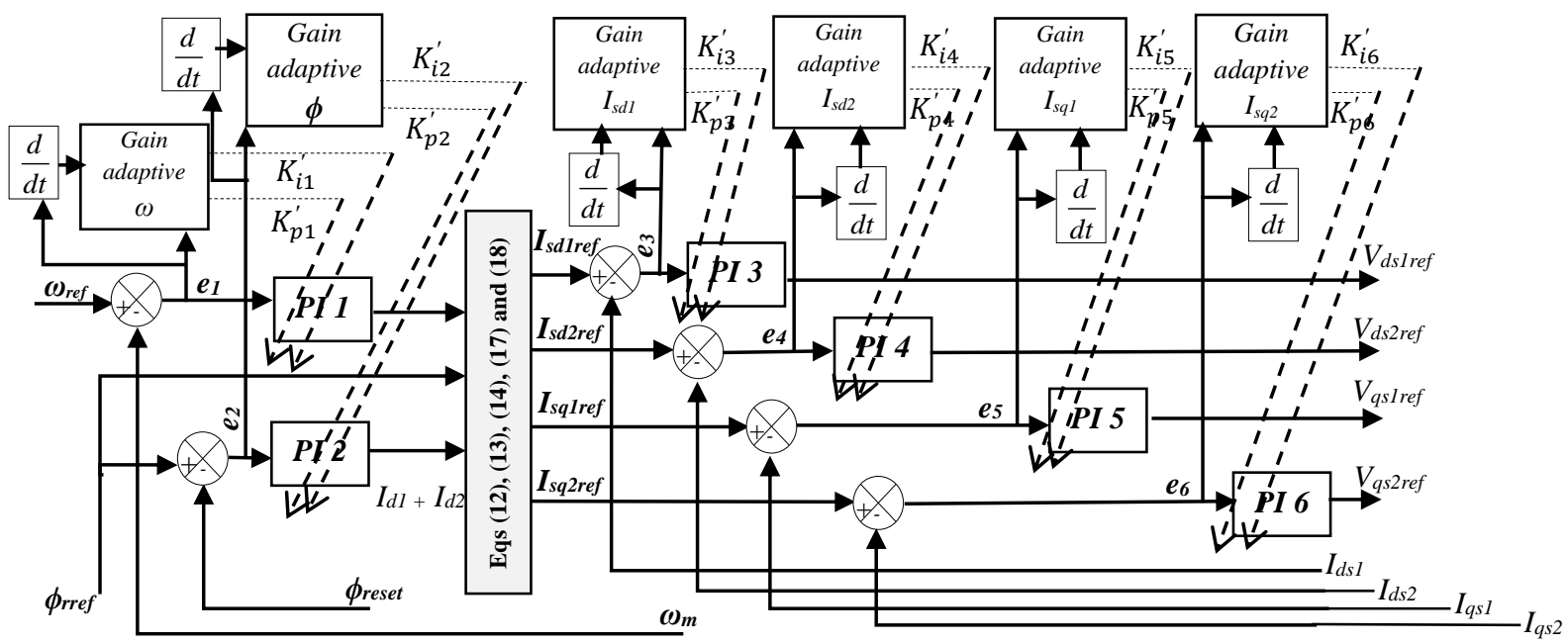

Figure.5 Block diagram of the IT2FGAPI for the direct rotor field oriented control (DRFOC) approach of the DSIM

The main advantage of this adaptation is to synthesized the six gains in the same time and in the same way, in order to maintain the performances static and dynamic desired of the variable speed during internal and external disturbances, while guaranteeing the stability and the robustness of the control of DSIM.

The block diagram of the IT2FGAPI for the DRFOC approach of the DSIM is shown in Fig. 5.

When $K_{p}^{\prime}$ and $K_{i}^{\prime}$ are obtained, $K_{p}$ and $K_{i}$ of the regulator PI are calculated from equation:

$$
\left\{\begin{array}{l}
K_{p}=\left(K_{p \max }-K_{P \min }\right) K_{p}^{\prime}+K_{P \min } \\
K_{i}=\left(K_{i \max }-K_{i \min }\right) K_{i}^{\prime}+K_{i \min }
\end{array}\right.
$$

The membership functions for the inputs $e_{j}$ and $\Delta e_{j}$ are defined in the range $[-1,1]$ and chosen to be triangular identical shapes as indicated in Fig. 6.

They are quantized into seven levels represented by a set of linguistic variables defined as follows:
(NB): negative big.
(PM): Positive medium.
(NM): negative medium.
(PB): Positive big.
(NS): Negative small.
(PS): Positive small.

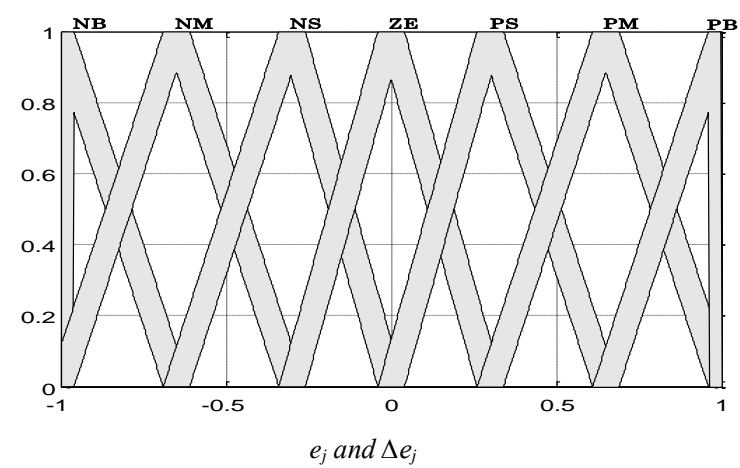

Figure.6 Type-2 fuzzy Membership functions of inputs $e_{j}$ and $\Delta e_{j}(j=1,2,3,4,5,6)$ for different PI
The membership functions for the outputs $K_{p j}^{\prime}$ and $K_{i j}^{\prime}$ are defined in the range $[0,1]$ as indicated in Fig. $7, K_{i j}^{\prime}$ is the value $K_{i}^{\prime}$ corresponding to the different PI, for example, $K_{i l}^{\prime}$ correspond to speed.

They are quantized into two levels represented by a set of linguistic variables defined as follows:

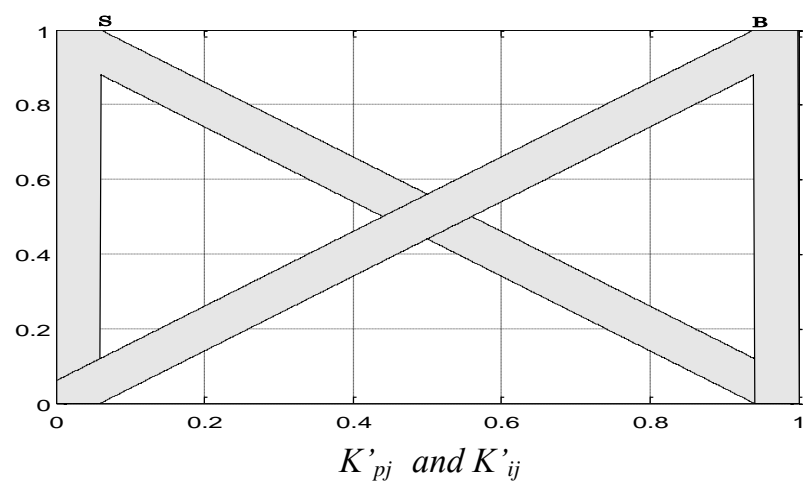

Figure.7 Type-2 fuzzy Membership functions of outputs $K_{p j}^{\prime}$ and $K_{i j}^{\prime}(\mathrm{j}=1,2,3,4,5,6)$ for different PI

Table 1 and table 2 shows the linguist rules for $K_{p j}^{\prime}$ and $K_{i j}^{\prime}$ used in the IT2FGAIP Controller [14].

\begin{tabular}{r|c|c|c|c|c|c|c||}
\multicolumn{3}{c}{ Table1: Fuzzy rules base for $K_{p j}^{\prime}$} \\
\cline { 2 - 10 } \multicolumn{1}{r|}{$\mathrm{e}_{\mathrm{j}}$} & & & & & & & \\
$\Delta \mathrm{e}_{\mathrm{j}}$ & $\mathrm{NB}$ & NM & NS & ZE & PS & PM & PB \\
\hline \hline NB & B & B & B & B & B & B & B \\
\hline NM & B & B & B & B & B & B & S \\
\hline NS & S & S & B & B & B & S & S \\
\hline ZE & S & S & S & B & S & S & S \\
\hline PS & S & S & B & B & B & S & S \\
\hline PM & S & B & B & B & B & B & S \\
\hline PB & B & B & B & B & B & B & B \\
\hline \hline
\end{tabular}


Table 2: Fuzzy rules base for $K_{i j}^{\prime}[14]$

\begin{tabular}{|c|c|c|c|c|c|c|c|}
\hline$\Delta \mathrm{e}_{\mathrm{j}}$ & NB & NM & NS & ZE & PS & PM & $\mathrm{PB}$ \\
\hline NB & B & B & B & B & B & B & $\mathrm{B}$ \\
\hline $\mathrm{NM}$ & $\mathrm{B}$ & $S$ & $\mathrm{~S}$ & $S$ & $\mathrm{~S}$ & $\mathrm{~S}$ & $\mathrm{~B}$ \\
\hline NS & B & B & $S$ & $S$ & $S$ & B & B \\
\hline $\mathrm{ZE}$ & B & B & B & $S$ & B & B & B \\
\hline PS & B & B & $\mathrm{S}$ & $S$ & $\mathrm{~S}$ & B & B \\
\hline $\mathrm{PM}$ & B & $S$ & $\mathrm{~S}$ & $S$ & $\mathrm{~S}$ & $S$ & $\mathrm{~B}$ \\
\hline PB & B & B & B & B & B & B & B \\
\hline
\end{tabular}

The processed surface is shown in Fig 8 and 9:

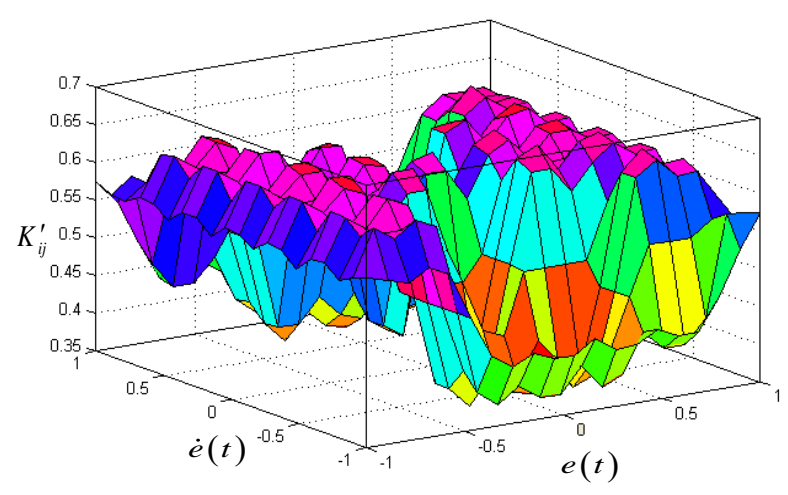

Figure.8 Surface for the gains $K_{i j}^{\prime}$

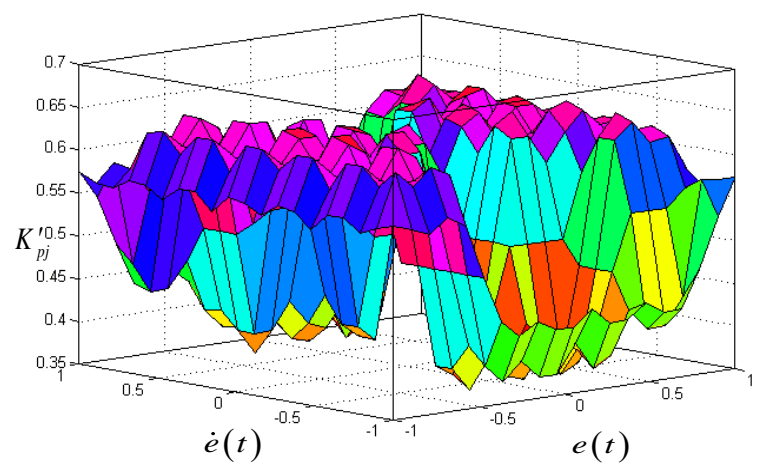

Figure.9 Surface for the gains $K_{p j}^{\prime}$

\section{Simulation results}

Several simulations were carried using the Matlab and Simulink® software the speed and flux regulation of $4.5 \mathrm{Kw}$ dual stator induction machine, the simulation results obtained are presented and discussed.

The nominal load disturbance torque (15 N.m) is suddenly applied at $3 \mathrm{sec}$, followed by a reversal of speed from $300 \mathrm{rad} / \mathrm{sec}$ to $1.5 \mathrm{sec}$ up to -300 during a period of 2 sec and after it is fixed a -300 , while the other parameters are held constant.

Following figures shows (10-15) the simulated responses of speed, electromagnetic torque, $\mathrm{d}-\mathrm{q}$ axis rotor field, d-q axis stator currents, and gains $K_{p}$ and $K_{i}$ for speed and flux respectively.

Figures (10 and 11) show that, the speed reaches its reference value at $0.5 \mathrm{~s}$ without no overshoot and with a negligible static error, the electromagnetic torque at starting exceed a value equal to $55 \mathrm{~N} . \mathrm{m}$. The excellent dynamic performance of torque control is represented in figure 11 , the reversal speed of $(300,-300 \mathrm{rad} / \mathrm{s})$ leads at the torque response reversal. At $3 \mathrm{~s}$, a $-15 \mathrm{Nm}$ load disturbance is applied; we have a positive influence of the couple that increases to keep the speed follow its reference value.

The decoupling of torque-flux is maintained in permanent mode.

In the present study, an integral squared error (ISE), integral absolute error (IAE) and integral time-weighted absolute error (ITAE) are utilized to judge the performance of the controllers. ISE, IAE and ITAE criterion is widely adopted to evaluate the dynamic performance of the control system. The index ISE, IAE and ITAE is expressed as follows [33]:

$$
\begin{aligned}
& I S E=\int_{0}^{T} e^{2}(t) d t \\
& I A E=\int_{0}^{T}|e(t)| d t \\
& I T A E=\int_{0}^{T} t|e(t)| d t
\end{aligned}
$$

For quantitative comparison between two methods, ISE, IAE and ITAE are used as the criterion.

Table. 3 shows the ISE, IAE and ITAE values of the simulation results using the fuzzy type-1 adaptive control proposed in [14] by Meliani et al and the proposed IT2FGAPI Controller. From the comparison, it can be seen that the performance is improved when using the proposed IT2FGAPI controller as compared to the fuzzy type-1 adaptive control proposed in [14]. Actually these performances index are obtained at the end of the simulation time $(\mathrm{T}=5 \mathrm{sec})$ with a sampling period $h=10^{-4}$. 
Table.3 Quantitative comparison between the proposed IT2FGAPI Controller and the fuzzy type-1 adaptive control proposed in [14]

\begin{tabular}{|l|c|c|c|}
\hline \multicolumn{2}{|c|}{ Index } & \multicolumn{1}{|c|}{$\begin{array}{l}\text { Control proposed } \\
\text { by Meliani et al } \\
\text { in [14] }\end{array}$} & $\begin{array}{l}\text { Proposed } \\
\text { IT2FGAPI } \\
\text { Controller }\end{array}$ \\
\hline \multirow{2}{*}{ ISE } & Speed & 18800 & 15040 \\
\cline { 2 - 4 } & flux & 0.284 & 0.220 \\
\hline \multirow{2}{*}{ IAE } & Speed & 94.714 & 75.774 \\
\cline { 2 - 4 } & flux & 0.405 & 0.3604 \\
\hline \multirow{2}{*}{ ITAE } & Speed & 20.586 & 16.486 \\
\cline { 2 - 4 } & flux & 0.1546 & 0.075 \\
\hline
\end{tabular}

The controller IT2GAIP rejects the load disturbance very rapidly and with a negligible steady state error, we can see the response of the proposed IT2FGAPI fast and robust from the point of view load variation.

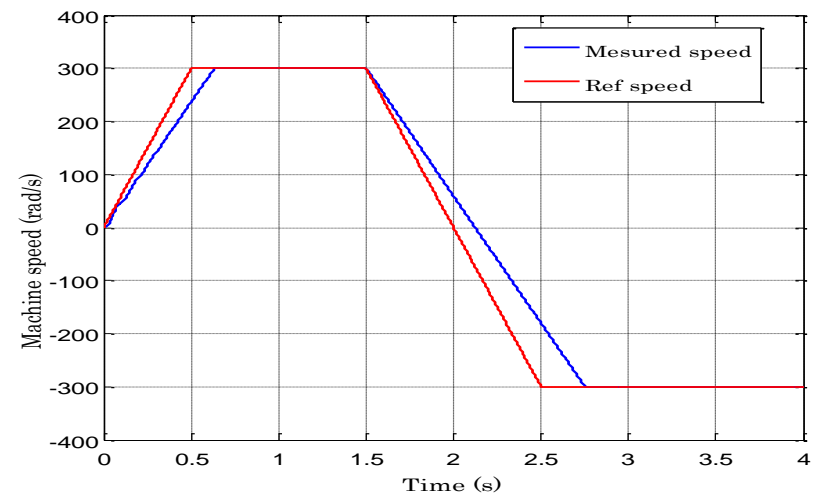

Figure.10 Simulated results of Speed response

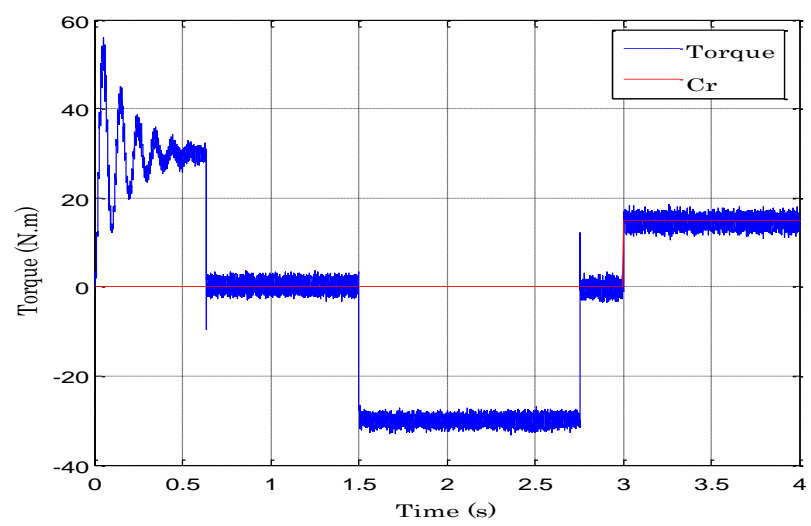

Figure.11 Simulated results of Torque under a load $\mathrm{Cr}=15 \mathrm{~N} . \mathrm{m}$ in $3 \mathrm{~s}$

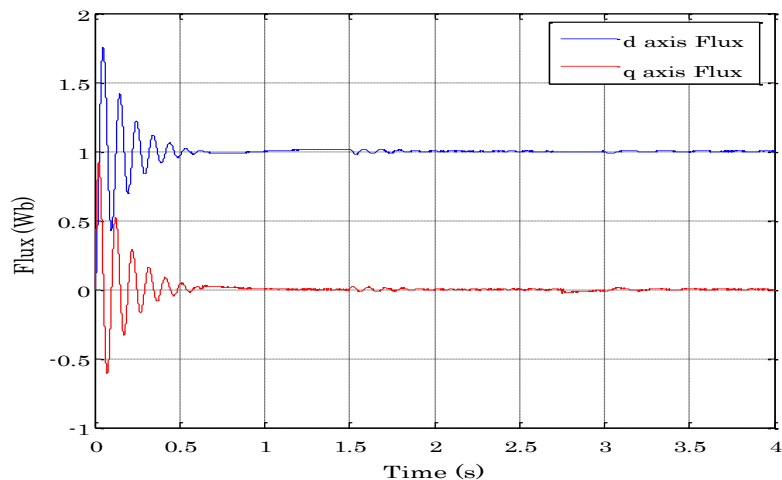

Figure.12 Simulated results of rotor flux

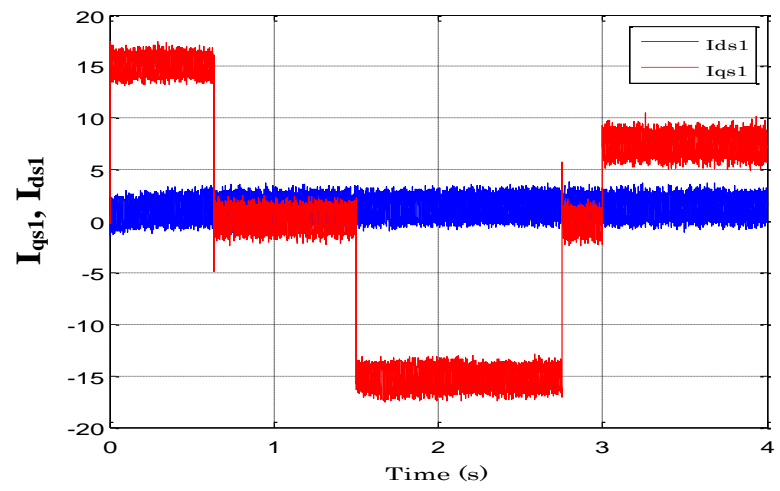

Figure.13 Simulated results of currents stator (Iqs1, Ids1) under a load $\mathrm{Cr}=15$ N.m in $3 \mathrm{~s}$

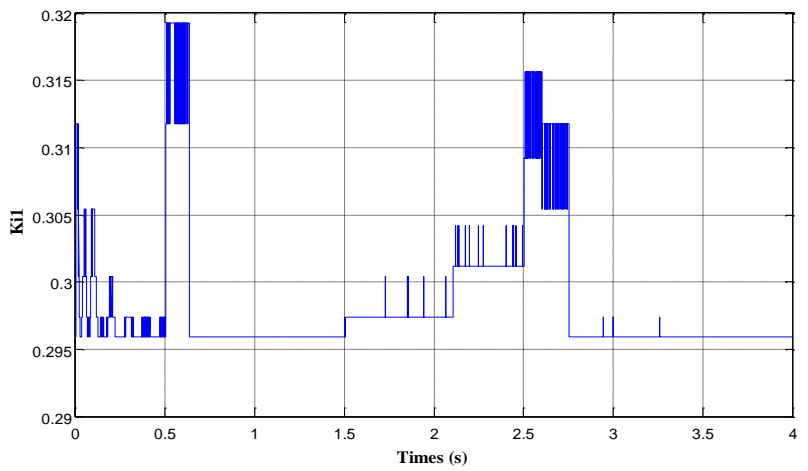

(a)

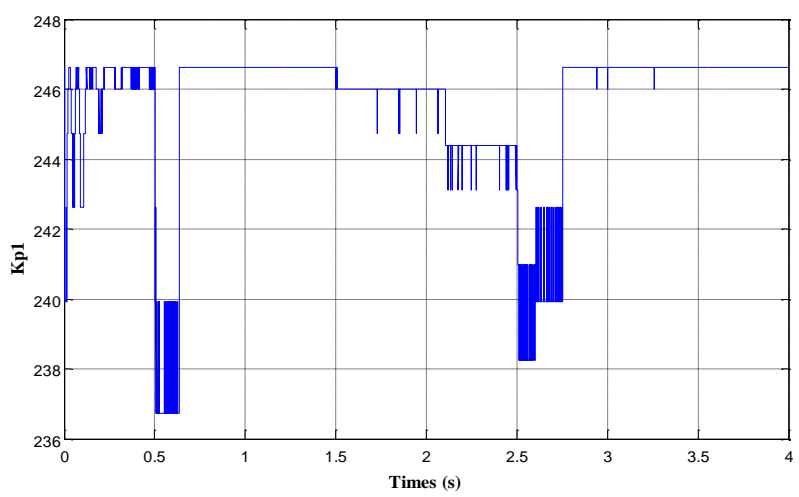

(b)

Figure.14 Simulated results of adaptive gains $K_{i l}$ (a) and $K_{p l}(\mathrm{~b})$ 


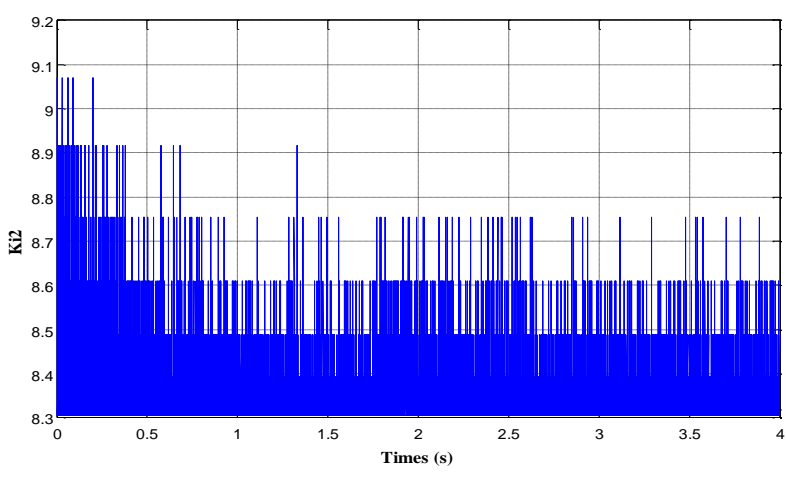

(a)

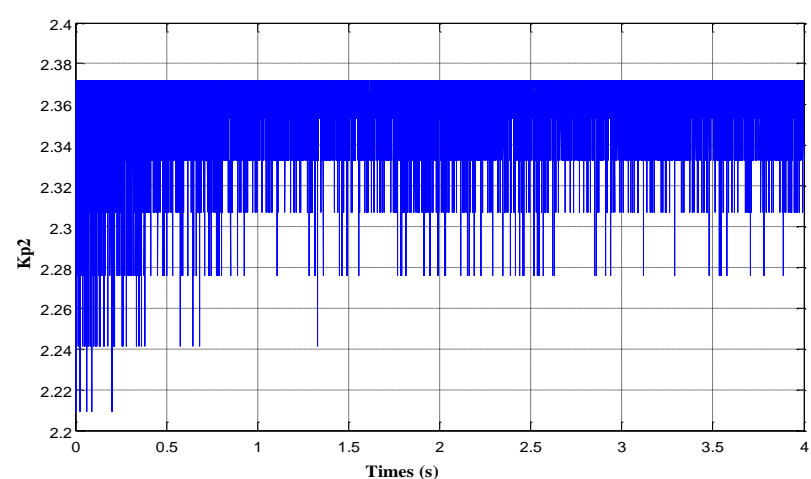

(b)

Figure.15 Simulated results of adaptive gains $K_{i 2}$ (a) and $K_{p 2}$ (b)

\section{Conclusion}

In this paper, the speed and flux control of the DSIM machine is simulated in MATLAB/Simulink by the use of IT2FGAPI control for the direct rotor field oriented control approach for DSIM drive system.

The simulation results have confirmed the efficiency of the IT2FGAIP controller and presented satisfactory dynamic performances, robust and assures global stability, it allows to have fast response without overtaking, settling time in speed response minimize and best disturbance rejection, for parameter variations and the external disturbances (sudden change in command speed, step change in load torque).

Finally, The IT2FGAIP controller is considered a major step in the evolution of intelligent control, no for the DSIM but for all types of machine. In the future work the experimental implementation of the proposed control scheme will be addressed.

\section{Appendix}

Table 4: Nomenclature.

\begin{tabular}{|l|ll}
\hline$V_{d s}, V_{q s,}, V_{d r}$, & $\begin{array}{l}\text { Stator and rotor voltages } \mathrm{d}-\mathrm{q} \text { axis } \\
V_{q r}\end{array}$ & components
\end{tabular}

\begin{tabular}{|l|l|}
\hline$I_{d s}, I_{q s}, I_{d r}$, & Stator and rotor currents d-q axis \\
$I_{q r}$ & components \\
\hline$\varphi_{s}, \varphi_{r}$ & stator - rotor flux \\
\hline$\varphi_{d}, \varphi_{q}$ & Stator flux d- q axis components \\
\hline$\omega_{s}, \omega_{r}$ & stator and rotor pulsation respectively \\
\hline$\omega_{\text {sref }, \omega_{\text {rref }}}$ & $\begin{array}{l}\text { Stator and rotor pulsation references } \\
\text { respectively. }\end{array}$ \\
\hline$\varphi_{\text {rref }}$ & rotor flux control reference \\
\hline$\varphi_{\text {drest }}, \varphi_{\text {qrest }}$ & rotor flux d- q axis estimated \\
\hline$R_{s}, R_{r}$ & Stator- Rotor resistance \\
\hline$C_{r}$ & Load torque \\
\hline$w$ & Mechanical speed \\
\hline$w_{g l r e f}$ & Sliding speed reference \\
\hline$C_{e m}$ & Electromagnetic torque \\
\hline$C_{e m r e f}$ & Electromagnetic torque reference \\
\hline$L_{s}, L_{r}$ & $\begin{array}{l}\text { Stator- and Rotor } \\
\text { respectively }\end{array}$ \\
\hline$L_{m}$ & Mutual inductance \\
\hline$J$ & Total inertia \\
\hline$p$ & Number of pole pairs \\
\hline$K_{f}$ & Friction coefficient \\
\hline$K_{p}, K_{i}$ & $\begin{array}{l}\text { Proportional and integral } \\
\text { respectively }\end{array}$ \\
\hline$e, \Delta e$ & Error and error derivative respectively \\
\hline & \\
\hline
\end{tabular}

Table 4: DSIM motor parameters

\begin{tabular}{c|c|c}
\hline Item & Symbol & Data \\
\hline DSIM Mechanical Power & $P_{w}$ & $4.5 \mathrm{~kW}$ \\
Nominal Voltage & $V_{n}$ & $220 \mathrm{~V}$ \\
Nominal Current & $I_{n}$ & $6.5 \mathrm{~A}$ \\
Nominal speed & $\omega_{n}$ & $300 \mathrm{rad} / \mathrm{s}$ \\
Pole pairs number & $p$ & 1 \\
Stators resistances & $R_{s l}=R_{s 2}$ & $3.72 \Omega$ \\
rotor resistance & $R_{r}$ & $2.12 \Omega$ \\
Stators self inductances & $L_{s 1}=L_{s 2}$ & $0.22 \mathrm{H}$ \\
rotor self inductance & $L_{r}$ & $0.006 \mathrm{H}$ \\
mutual inductance & $L_{m}$ & $0.3672 \mathrm{H}$ \\
Moment of inertia & $J$ & $0.625 \mathrm{~kg} . \mathrm{m}^{2}$ \\
friction coefficient & $K_{f}$ & $0.001 \mathrm{Nms} / \mathrm{rad}$ \\
Nominal Frequency & $f$ & $50 \mathrm{~Hz}$ \\
\hline
\end{tabular}

\section{References}

[1] Z. Tir, Y. Soufi, M.N. Hashemnia, O.P. Malik, and K. Marouani, "Fuzzy logic field oriented control of double star induction motor drive", Electrical Engineering, DOI: 10.1007/s00202016-0377-2, pp.1-9, May 2016.

[2] A. Kalantari, M. Mirsalim, and H. Rastegar, "Adjustable speed drive based on fuzzy logic for a dual three phase induction machine", In: Proc. of 7th International conference on modeling and simulation of electric machines, converters and systems, Montreal, pp.18-21, 2002. 
[3] L. Benalia, Control of a double feed and double star induction machine using direct torque control, in Torque Control, M. T. Lamchich (Ed), chapter 5, In Tech, pp.113-126, Croatia, 2011.

[4] B. Ghalem, and A. Bendiabdallah, "Six-Phase Matrix Converter Fed Double Star Induction Motor", Acta Polytechnica Hungarica, Vol.7, No.3, pp.163-176, 2010.

[5] B. Ghalem, and A. Bendiabdallah, "A Comparative Study between Two Control Strategies for Matrix Converte", Advances in Electrical and Computer Engineering Journal, Vol.9, No.2, pp.23-27, 2009.

[6] Z. Tir, O.P. Malik, and AM. Eltamaly, "Fuzzy logic based speed control of indirect field oriented controlled Double Star Induction Motors connected in parallel to a single sixphase inverter supply", Electric Power Systems Research, Vol.134, pp. 126-133, 2016.

[7] S. Lekhchine, T. Bahi, and Y. Soufi, "Indirect rotor field oriented control based on fuzzy logic controlled double star induction machine", International Journal of Electrical Power \& Energy Systems, Vol.57, pp.206-211, May 2014.

[8] M.M. Rezaoui, A. Kouzou, M.O. MAHMOUDI, and L. NEZLI, "Comparison performances between two matrix converters [3x3] and [3x5] supplying a multi-phases induction machine", Journal of Electrical Engineering, Vol.16, No.1, pp.1-11, 2016.

[9] D. Hadiouche, H. Razik, and A. Rezzoug, "Study and simulation of space vector PWM control of double-Star Induction Motors", In: Proc. of the VII IEEE International Power Electronics Congress, Acapulco, Mexico, pp. 42-47, 2000.

[10] K. Loukal, and L. Benalia, "Interval type-2 fuzzy gain-adaptive controller of a doubly fed induction machine (DFIM)", Journal of Fundamental and Applied Sciences, Vol.8, No.2, pp.470-493, 2016.

[11] B. Heber, X. Longya, and Y. Tang, "Fuzzy logic enhanced speed control of an indirect field-oriented induction machine drive", IEEE Trans. Power Electronics, Vol.12, No.5, pp.772-778, 1997.

[12] H. Amimeur, R. Abdessemed, D. Aouzellag, E. Merabet, and FA. Hamoudi, "Sliding mode control associated to the field-oriented control of dual-stator induction motor drives", Journal of Electrical Engineering, Vol.10, No.3, pp.713, 2010.

[13] H. Zhou, J.N. Duan, and Z. Zhou, "A simplified adaptive interval Type-2 fuzzy control in practical industrial application", Journal of Central South University, Vol.21, No.7, pp.2693-2700, 2014.

[14] B. Meliani, A. Meroufel, and H. Khouidmi, "Fuzzy Gain Scheduling of PI Controller for Dual Star Induction Machine fed by a Matrix Converter", Carpathian Journal of Electronic and Computer Engineering, Vol.5, No.6, pp.77-82, 2012.

[15] T. Laamayad, F. Naceri, R. Abdessemed, and S. Belkacem, "fuzzy adaptive controller based on the lyapunov theory for control of the dual star induction machine", Journal of Electrical Engineering, Vol.12, No.2, pp.47-57, 2012.

[16] T. Laamayad, F. Naceri, R. Abdessemed, and S. Belkacem, "A fuzzy sliding mode strategy for control of the dual star induction machine", Journal of Electrical Engineering, Vol.13, No.1, pp.1-8, 2013.

[17] H. Amimeur, D. Aouzellag, R. Abdessemedn, and K. Ghedamsi, "Slinding mode control of a dual-stator induction generator for wind energy conversion systems", International Journal of Electrical Power \& Energy Systems, Vol.42, No.1, pp.60-70, 2012.

[18] T.S. Radwan, "Perfect speed tracking of directe torque controlled induction motor drive using Fuzzy logic", In: Proc. International Conf. Power Electronics and Drives Systems, PEDS,IEEE, Kuala Lumpur, Malaysia, pp.38-43, 2005.

[19] F. Hamidia, A. Abbadi, and M.S Boucheri, "Direct torque controlled Dual Star Induction Motors (in open and closed loop)", In: Proc. of the 4th IEEE International Conference on Electrical Engineering, pp.1-6, Boumerdes, Algeria, 2015.

[20] E. Y. Y. Ho, and P. C. Sen, "Decoupling control of induction motor drives", IEEE Transactions on Industrial Electronics, Vol.35, No.2, pp. 253-262, 1988.

[21] H. Khouidmi, A. Massoum, and A. Meroufel, "Dual star induction motor drive: Modelling, Supplying and control", International journal of electrical and power engineering, Vol.5, No.1, pp.28-34, 2011.

[22] I. Takahashi, and S. Asakawa, "Ultra-wide speed control of induction motor covered 10A6 Range", IEEE Transactions on Industry Applications, Vol.25, pp.227-232, 1987.

[23] Boglietti, P. Ferraris, M. Pastorelli, and C. Zimaglia, "Induction motors field oriented control based on averaged parameters", In: Proc. of the IEEE Conference on Record of Industry 
Applications Society Annual Meeting, USA, pp.81-87, 1994.

[24] Q. Liang, and J. Mendel, "Interval type-2 fuzzy logic systems: theory and design", IEEE Transactions on Fuzzy Systems, Vol.8, No.5, 2000.

[25] J. Mendel, Uncertain rule-based fuzzy logic systems, introduction and new directions, Vol.1, Prentice-Hall, New Jersey, USA, 2001.

[26] O. Castillo, and P. Melin, "A review on the design and optimization of interval type-2 fuzzy controllers", Applied Soft Computing, Vol.12, No. 4, pp.1267-1278, 2012.

[27] R. Juan, O. Castillo, P. Melin, and A. Rodríguez-Díaz, "A hybrid learning algorithm for a class of interval type-2 fuzzy neural networks", Information Sciences: an international journal, Vol.179, No.13, pp.21752193, 2009.

[28] R. Martínez, O. Castillo, and L. Aguilar, "Optimization of interval type-2 fuzzy logic controllers for a perturbed autonomous wheeled mobile robot using genetic algorithms", Information Sciences: an international journal, Vol.179, No.13, pp.2158-2174, 2009.

[29] D. Wu, and W. Tan, "A simplified type-2 fuzzy logic controller for real-time control", Instrument Society of America Transactions, Vol.45, No.4, pp.503-510, 2006.

[30] O. Castillo, M. Marroquín, P. Melin, F. Valdez, and J. Soria, "Comparative study of bio-inspired algorithms applied to the optimization of type-1 and type-2 fuzzy controllers for an autonomous mobile robot", Information Sciences, Vol.192, pp.19-38, 2012.

[31] A. Hazzab, I. K. Bousserhane, M. Zerbo, and P. Sicard, "Real Time Implementation of Fuzzy Gain Scheduling of PI Controller for Induction Motor Machine Control", Neural Processing Letters, Vol.24, pp.203-215, 2006.

[32] V. Jeyalakshmi, and al, "On Line Tuning of intelligent controller for induction drive system", International Journal of Engineering Science and Technology, Vol.2, No.10, pp.5350-5356, 2010.

[33] O. Castillo, and P. Melin, Type-2 fuzzy logic, Theory and applications, Vol.223, SpringerVerlag, Berlin, Germany, 2008. 